\title{
Familiarisation Aboard Ships of Croatian and Montenegrin Officers
}

\author{
Pero Vidan ${ }^{a}$, Tatijana Dlabačb ${ }^{\mathrm{b}}$ Goran Jerkovića
}

New officers joining the ship must be aware of their obligations regarding information of security and safety on board. Furthermore, familiarisation includes technical skill related to ships' equipment. Because of the lack of time during handover due to a short time of cargo operations in port, handover is often inadequate. Familiarisation should last more than a month. Officers' contracts are usually shorter than familiarisation process. Familiarisation time and lack of familiarisation are considered as period of great risk of human error.

In this paper the authors research familiarisation and handover as safety aspects.

\section{KEY WORDS}

$\sim$ Familiarisation

$\sim$ Handover

$\sim$ Croatian Officers

$\sim$ Montenegrin Officers

\author{
a. University of Split, Faculty of Maritime Studies, Split, Croatia \\ e-mail: pvidan@pfst.hr \\ b. Maritime Faculty of Kotor, University of Montenegro, Kotor, Montenegro \\ e-mail: tanjav@ac.me
}

\section{INTRODUCTION}

According to the research conducted by the British Marine Accident Investigation Board (MAIB), Canadian Transportation Safety Board (TSB), and Australian Transportation Safety Board (ATSB), which carefully studied 350 cases of maritime accidents, 82 to $85 \%$ of all accidents were either directly initiated by human error or were associated with human error by means of inappropriate human responding to threat situations. The incidence of human error in maritime shipping industry does not arise exclusively from the operator's failure. There is a wide range of factors contributing to the occurrence of human error. One of them is modern technology. Although all equipment aboard has to be standardized according to the Safety of Life at Sea-SOLAS Convention requirements, it is considered that inadequately designed equipment made difficulties to operators and caused $1 / 3$ of major sea accidents. Another aspect affecting the human error is the interaction between the technology and human beings i.e. lack of training and familiarisation with equipment's operation procedures. A study performed by R. Ziarati and M. Ziarati reveals that inadequate use of navigation equipment causes $28 \%$ of accidents (Baker et al., 2005). In this case, "inadequate" refers to the use of equipment in an inappropriate manner due to insufficient training or non-adapted equipment.

Most of regulations and standards applying to ships do not address complex issues such as cognitive activities associated with implementing new technologies on board ships. The number of standards and regulations that exclusively deal with the relationship between on-board automation and human beings are relatively low. Almost $80 \%$ of the regulations in 
maritime shipping industry refer to technical rules, whereas the remaining $20 \%$ refer to humans (Baker et al., 2005).

For instance, SOLAS Chapter V, regulation 15, lays out the principles relating to bridge design and design of navigational systems and equipment. Operators have to cope with the equipment produced by various manufacturers competing in additional abilities not obligatory according to SOLAS requirements and may be used very rarely, bur can lead to confusion making the overall bridge system inconsistent. The equipment installed on ships of the same type and purpose may greatly vary from vessel to vessel, so that operators have to adjust to a new equipment layout, differing specifications etc., which represents a potential source of failure. The American National Transport Safety Board states that almost one out of three failures is caused by inadequate equipment design, where the lack of standardisation is the key contributing factor (Albayrak et al., 2010).

According to British psychologist Lissiane Banbridge, the core of the problem is that equipment manufacturers and their designers often tend to displace a human being out of the system wherever possible but keep on requiring an operator to carry out the tasks for which they have not found adequate solution. One of the problems that may arise in automated systems is undoubtedly the poorly designed technology that does not allow an adequate interaction between the human being and the equipment. If the interaction between a device and an operator is not ergonomic, it is likely that the operator will be overloaded and confused by the information provided by the device. For example, in case when a number of alarms are given at the same time, it is possible that critical warnings remain unnoticed (Vidan et al., 2015).

Modern integrated systems of shipping management have considerably contributed to the increased safety of sea traffic. Yet, it is necessary to introduce changes within these systems in order to reduce the share of human error in causing accidents. For instance, SOLAS regulations define the layout of the bridge, but do not define its precise design. This allows substantial room for the manufacturers who, apart from meeting SOLAS requirements, frequently install additional options to the equipment in order to boost their price and competitiveness on the market. In this way, seafarers are moved to a less favourable position, as the design of technologies forming a modern operating system has not been developed on the basis of the seafarers' needs and is likely to lead an operator to making a mistake. In order to use the available technology in a fast and efficient way, the operator has to be thoroughly familiar with all the equipment specification and modes of use and operation. To achieve this, the operator has to complete adequate training and familiarisation which will help him/her to identify all advantages and drawbacks of the equipment. Proficiency and familiarisation are the key factors in the prevention of failures and safety hazards. However, although a large number of seafarers employed by forward-thinking maritime companies attend various forms of training in order to acquire certificates of competence in operating specific systems, this does not guarantee that a seafarer will perform his/her duties using the very device and the very model that he/she familiarised with during training.

The problem of insufficient use of the equipment still exists. Some of the primary causes of failures resulting in poor exploitation of modern systems are shown in Figure 1. One of the essential aspects of this issue is the fact that the equipment often differs considerably from vessel to vessel, and seafarers rarely serve the same or similar vessels throughout their career. The end result is the superficial familiarisation with the system. Although every device has a user's manual offering certain information and instructions to the operator, the latter is often unable to read the manual thoroughly upon joining the ship due to the lack of time. Consequently, this leads to a situation where the operator is forced to handle the devices he/she is not entirely familiarised with. The operator improvises, relies on the previous experience and transfers it from the previous devices to the new ones that do not necessarily have the same mode of operation. These situations open up huge potential for misinterpreting the information that is provided by automated systems (Foord et al., 2006).

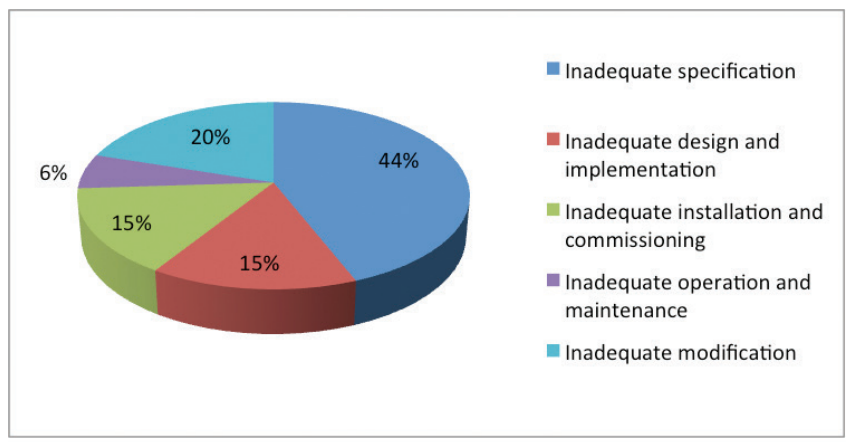

Figure 1.

Primary causes of failures in modern exploitation systems

\section{FAMILIARISATION AND HANDOVER ABOARD}

The new officer crewmembers joining the ship must be aware of their obligations regarding the use of equipment, security and safety on board. The main purpose of familiarisation is to introduce new officers with important safety procedures on board, emergencies and proper use of ship technology. The captain shall appoint a qualified person responsible for training new members of the crew. Although all members of the crew joining a ship must pass a standardized training by Standards of Training, Certification and Watch-keeping for Seafarers-STCW, 
there are specific instructions and requirements specific to each ship:

- Instructions on SOLAS and International Convention for the Prevention of Pollution from Ships-MARPOL

- Important features of muster list

- Guidelines on how to tackle all kinds of emergency situations on ships

- Important documents and publications of ships

- Ship's Fire Control Plan

- Different types of fire-fighting appliances and procedures to use them

During familiarization the officer will be introduced with specific details of his job depending of the type of ship and organization of crew on board. This familiarisation also includes reading manuals of new engines and equipment in order to be able to properly use them.

Except in the performance of watch-keeping at sea and in port, the new crew members will be informed of all standing orders of the chief engineer or master.

Training for lifesaving appliances and fire appliances should be completed as soon as possible and no later than two weeks after the receipt of the ship or the provisions of a single company ship owner (Unknown, 2012).

The familiarization training will include:

- $\quad$ Duties to eeks after joining the ship (Unknown, 2015)

Shipboard audits and port-state control results show this to be a weak area. In many cases, the crew is unfamiliar with the ship-specific and pollution-prevention equipment (Navigational Claims Brochure, 2014).

Handover is a process during the exchange of duties of two crew members of the same rank. It is usually obtained in ports. It is a normal procedure on board ships that the new crew member will be given handover of his or her duties by the person who is being relieved. During handover the new crew member has been introduced with the ship, her equipment, specific details of technology of ship and also duties. During handover, information about vessel documentation, accounts, logs etc. are usually exchanged (Shahrokh, 2015; Squire, 2015).

\section{HYPOTHESIS}

Handover is usually short and inadequate because of the lack of time in ports. It depends on the educational background of the officer, with the same or similar vessel and/or equipment.

Familiarisation is a process which starts after embarkation and lasts for 30-45 days. Because of hi-tech ships it can exceed 45 days. Familiarisation is performed usually according to the International Safety Management Code-ISM between the new crew member and a crew member designated by a senior officer. It depends on education of the officer.

\section{METHODOLOGY}

A research has been performed by the Faculty of Maritime Studies in Split and Maritime Faculty in Kotor with Croatian and Montenegrin officers using questionnaires. The subjects of the questionnaire were the quality of familiarisation and handover in their companies. The questionnaires were anonymous, but with the telephone number of the surveyed to enable checking. $20 \%$ of the questionnaires were checked.

Questionnaires were written in the Croatian and Montenegrin languages. Croatia and Montenegro have similar systems of education of seafaring officers. After the secondary maritime school seafarers become cadets or engine apprentices. After a year of navigation as cadets, they sit for an exam in the Harbour Master's Office for officer in charge on vessels of $500 \mathrm{GT}$ or more (STCW II/1) or engineer officer in charge on vessels with propulsion of $750 \mathrm{~kW}$ or more (STCW III/1). Captains of vessel of 3,000 GT or more (STCW II/2) and chief engineers on ships with propulsion of 3,000 kW and more (STCW III/2) have to have higher education (maritime faculty) degree and at least one year of experience as chief mate (deck) or 2nd engineer (engine), or 3 years of experience as deck officer (deck) or 3 years' experience as engineer officers (engine). After that they have to pass an exam in the Harbour Master's Office.

\section{RESULTS}

200 officers were surveyed, 113 Croatian and 87 Montenegrins. From the total number of 200 officers, 65 (32.5\%) of them are 25-30 year old, 79 (39.5\%) are 30-40 years old, 33 (16.5\%) are in the range between 40 and 50 years of age and only $23(11.5 \%)$ are older than 50 . Officers are experienced, with less than 4 years of navigation (7\%), 4-10 years (29\%) and more than 15 years of navigation (29\%) (Figure 2).

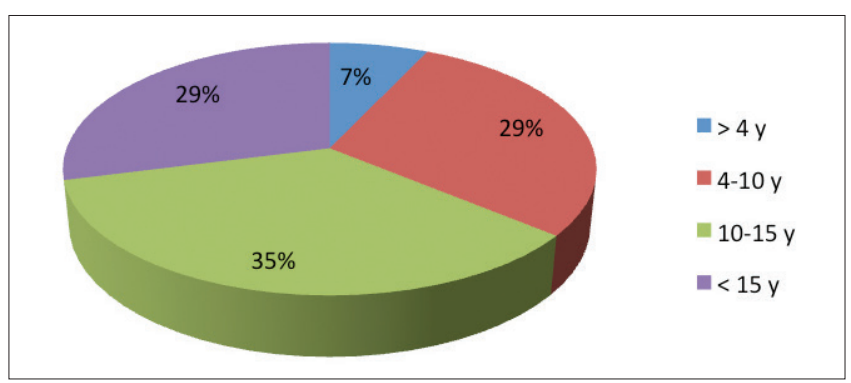

Figure 2.

Experience of navigation $(n=200)$.

47 (26\%) officers graduated from a maritime faculty and 133 (74\%) finished secondary maritime school (Figure 3). 


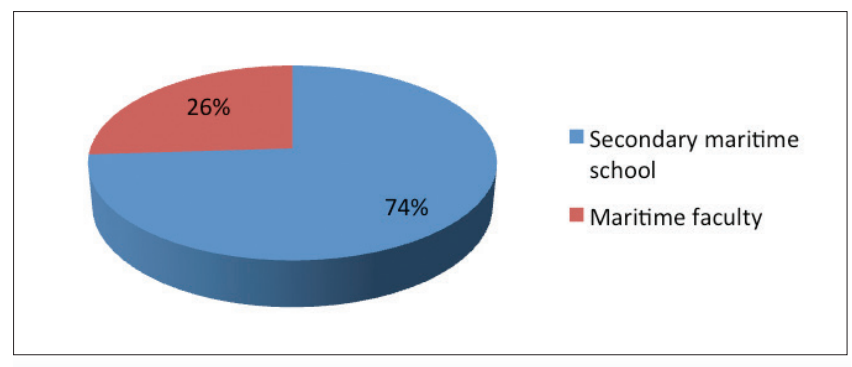

Figure 3.

Education of officers $(n=200)$.

To the question about duration of handover, 64 (31 \%) officers answered "up to 2 hours". Duration of 2-4 hours was chosen by 28 officers ( $14 \%), 4-6$ hours by 26 officers (13\%). More than 6 hours was the choice of 84 officers (42\%) (Figure 4).

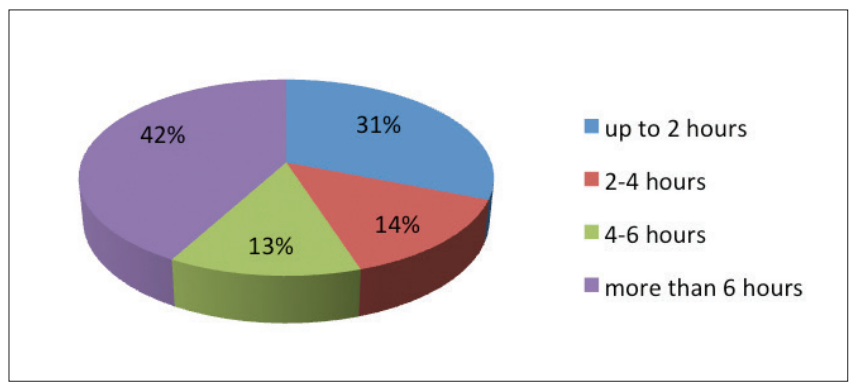

Figure 4.

Duration of handover $(n=200)$.

The duration of familiarisation up to 7 days was stated by 174 officers (87\%), 20 officers (10\%) had 7-15 days of familiarization. 4 (2\%) officers had 15-30 days' familiarisation. 2 officer (2\%) replied about 30-45 days' familiarization (Figure 5)

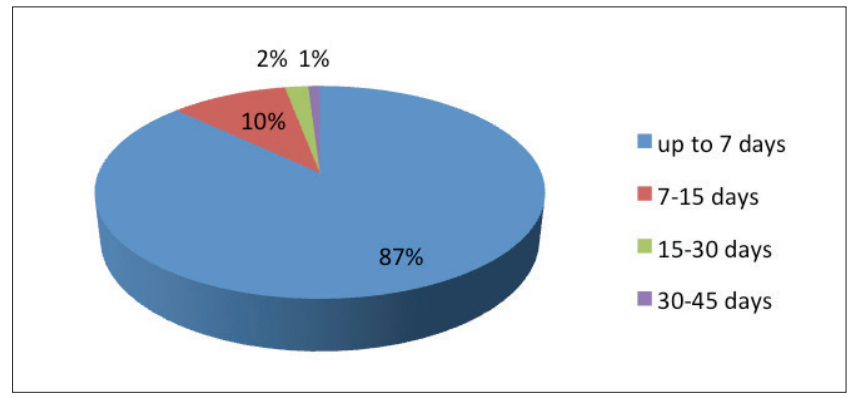

Figure 5.

Duration of familiarisation $(n=200)$
From the total number of 200, 102 officers considered handover as sufficient and 88 of the officers surveyed considered familiarisation as sufficient.

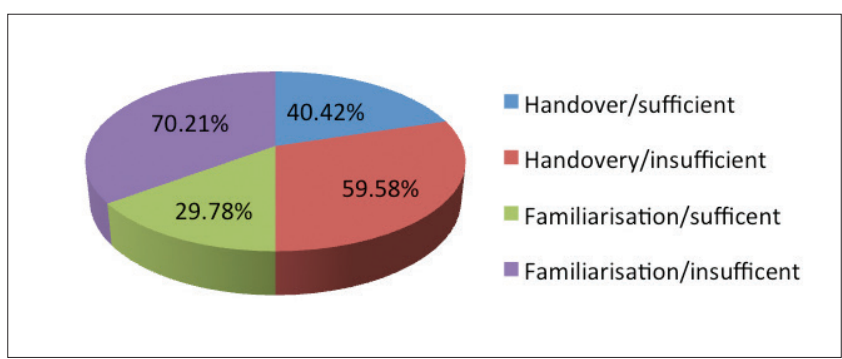

Figure 6.

Answers of officers who graduated from maritime faculty $(n=47)$.

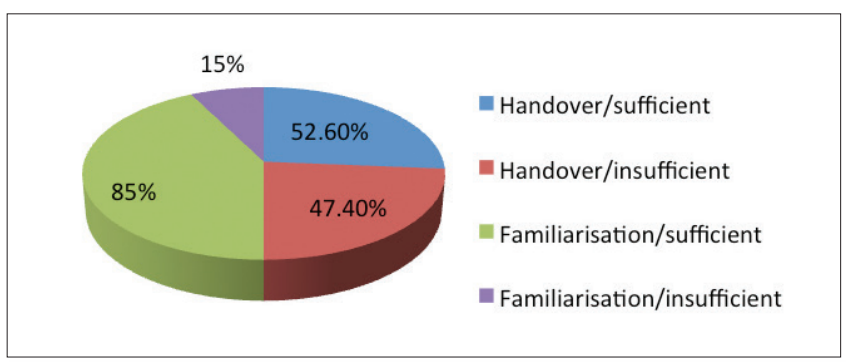

Figure 7.

Answers of officers who finished maritime secondary school $(n=133)$.

From the total number of 133 officers who finished maritime faculty, 28 considered handover as insufficient and 33 thought the same about familiarisation (Figure 6). The officers who finished only maritime secondary school thought that handover was insufficient were 63 and 20 thought the same about familiarisation (Figure 7). $58 \%$ of officers sail on board

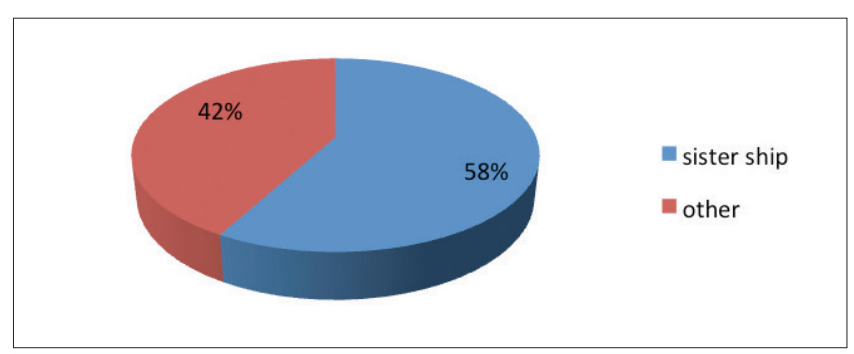

Figure 8.

Answers about similarity of vessel where officers sailing. 
sister ships. The remaining $42 \%$ do not sail on board sister ships, but on ships using the same technology.

\section{DISCUSSION}

200 questionnaires are not a representative number, but the research shows significant phenomena. There has not been a similar research up to date, so that the amount of deviation from the control number could not be calculated. The authors expect this survey to lead to a future research about familiarisation of crew aboard ships.

Most of the officers surveyed finished a secondary maritime school-74 \% (Figure 5) and most of the surveyed have experience of sailing 10-15 years (Figure 4). Comparing Figure 6, which shows answers of officers graduated from a maritime faculty, and Figure 7, which shows answers provided by those having finished a secondary maritime school, it's obvious that handover and familiarisation do not depend on the education level. In a future survey it is recommended to compare how experience in sailing and training affects familiarisation and handover.

Results are the same for Croatian and Montenegrin officers, so there was no need for a detailed analysis by nationality.

$42 \%$ of the surveyed answered that they had handover longer than $42 \%$ which s consider ad enough (Figure 4). $87 \%$ of surveyed had familiarisation up to 7 days which consider as insufficient. Most officers (Figure 6) are satisfied with time of familiarisation, although it was up to 7 days (Figure 4). This result is confused but it is consequence of fact that $58 \%$ of officers have sister ship as last ship of sailing (Figure 8 ), and $98 \%$ officers has last ship with same technology as previous.

Although $42 \%$ of surveyed officers had handover longer than 6 hours, $59.58 \%$ of officers considered this period as insufficient. Taking into consideration Figure 8 , it is to conclude that handover requires more time. The interview with the officers also discovered that, in an inversely proportional manner the ship administration has recently increased while handover has become shorter.

\section{CONCLUSION}

Familiarisation and handover are considered as very important for the safety and security of ship. Technological innovations prolong them. Seafarers+ contracts become shorter. In some cases, e.g. on offshore vessels, where contracts have duration of one month aboard and one month at home, familiarisation can last as long as the contract period.

STCW and International Maritime Organisation-IMO are introduced with the problem of familiarisation and handover. Because of this, they prescribed familiarisation trainings for special ships and equipment.
Shippers, in order to reduce familiarisation time and handover, usually embark seafarers, especially officers on sister ships or ships of the same technology.

This survey includes 200 seafarers, officers from Croatia and Montenegro. There was no previous research about familiarisation and handover, so this statistics does not include control group and deviation data.

In a future research it is necessary to include data about experience and how experience affects familiarisation and handover. For better results, officers should not navigate on sister ships. It is also recommended to include shippers and agencies that embark seafarers and try to research their statements and opinions.

During this survey, a researcher found out that in a future survey it would be very important to analyse how officer rank and the size of ship and engine affect the time of handover and familiarisation.

For the representativeness of the number of surveyed, it is necessary to extend the survey to other nations with different systems of education and promotion and increase the number of surveyed to at least 1,000.

\section{REFERENCES}

Albayrak, T. and Ziarati, R., (2010), Training: Onboard and Simulation Based Familiarisation and Skill Enhancement to Improve the Performance of Seagoing Crew, Proc. International Conference on Human Performance at Sea HPAS 2010, Glasgow, Scotland, UK,June 16 - 18, pp. 11 - 21., available at: http://www.egmdss. com/pictures/press/2010_06_16_tr_HPAS2010_improve_the_performance_of_ seagoing_crew.pdf

Baker, C.C. and McCafferty, D.B., (2005), Accident database review of human element concerns: what do the results mean for classification?, Proc. International Conference on Human Factors in Ship Design, Safety and Operation, London, UK, February 23 - 24, availabe at: http://citeseerx.ist.psu.edu/viewdoc/download?doi=1 0.1.1.437.6892\&rep=rep $1 \&$ type $=$ pdf

Bielic,,T. and Zec, D., (2004), Influence of Ship Technology and Work Organisation on Fatigue, Pomorski zbornik, 42 (1), pp. 263-276.

Foord, A. G. and Gulland, W. G., (2006), Can technology eliminate human error?, available at: http://wildeanalysis.co.uk/system/downloads/371/original/Can Technology_Eliminate_Human_Error.pdf, [accessed 21 April 2015.].

Navigational Claims Brochure, (2014), available at: http://www.swedishclub.com/ upload/Publications/navigational-claims-brochure.pdf, [accessed 11 February 2015.].

Shahrokh, K., (2015???), Familiarisation on Board, available at: http://www.he-alert. org/filemanager/...-/he01095.pdf, [accessed 12 June 2015.].

Squire, D., (2006), The Human Element in Shipping, available at: http://www. he-alert.org/filemanager/root/site_assets/standalone_pdfs_0355-/he00350.pdf, [accessed 1 September 2015.].

Unknown, (2006), Guidance to Masters, 2nd Edition, Arendal, Norway: Gard, available at: http://www.gard.no/Content/20651969/GTM_web.pdf, [accessed 1 September 2015.]. 
Unknown, (2013), Familiarization for New Crew Members on Board of the Ship, available at: http://sea-jobs.net/encyclopediaen/190, [accessed 1 September 2015.].

Unknown, (2012), Procedure for Ship Familiarization for New Crew Members on Ships, available at: http://www.marineinsight.com/misc/marine-safety/procedurefor-ship-familiarization-for-new-crew-members-on-ships/, [accessed 30 august 2015.].
Vidan, P., Bukljaš Skočibušić, M. and Rubić, J., (2015), Influence of New Technology on Human Error, Proc. 17th International Conference on Transport Science, Portorož, Slovenia, May 21 - 22, pp. 554-562. 